Corresponding Author: a.omer@psau.edu.sa.

Received 11 November 2019 Accepted 02 February 2020 Published 31 March 2020

Production and Hosting by Knowledge E

() Ahmad AbdulAzeem Abdullah. This article is distributed under the terms of the Creative Commons

Attribution License, which permits unrestricted use and redistribution provided that the original author and source are credited.

Editor-in-Chief:

Prof. Mohammad A. M. Ibnouf
Research Article

\section{National Competency Frameworks for Medical Graduates: Is it Time for the "Sudanmeds"?}

\section{Ahmad AbdulAzeem Abdullah, MBBS, MSc, MD, MRCSEd, MMED}

Department of Surgery, College of Medicine, Prince Sattam bin Abdulaziz University, Alkharj 11942, Saudi Arabia

\section{Abstract}

Competency-based medical education has emerged recently as a novel model of medical training driven by its ability to reconcile the desired attributes in future physicians and address the overarching and demanding issues of the discipline in this century. The rising concerns of social accountability, patient safety, and cost effectiveness of medical education programs have contributed significantly to the popularity of this paradigm worldwide. This is translated in turn to the evolution of national competency frameworks for medical graduates that are increasingly implemented in different jurisdictions to standardize and ensure equivalent outcomes of medical curricula and readiness of their graduates to better serve their communities. Medical education in Sudan is deeply rooted in the history of the nation and the continent and is tinged with remarkable success and achievements. It is challenged nowadays with unprecedented expansion in basic medical education which may hinder the quality of medical schools' programs and their graduates. This article explores the feasibility of one such framework in Sudan: the "SudanMeds" to ensure minimum standards and comparability of medical schools' curricula and their outcomes across the Country. The framework would also arm the regulatory bodies with a tool for accreditation and recognition of basic medical education programs in Sudan and reflect quality assurance in their settings. Once this approach is deemed feasible, the contribution of all stakeholders from the highest top to the bottom - the government, the regulatory bodies, the public and civil organizations, and the medical schools' community - is required to allow for creation, implementation, and follow-up of the "SudanMeds" framework.

Key words: Sudan, competency-based medical education, national competency frameworks, medical schools, basic medical education

\section{Introduction}

\section{A global drive for competency-based medical education (CBME)}

The trajectory of medical education has been marked in the last few decades with growing enthusiasm in competency-based education [1-5]. This paradigm came at the 
forefront of interests of many medical schools worldwide driven by the increasing complexity and changing roles of physicians in this century $[3,6]$. The interest in CBME has spiked recently in response to the rising awareness and expectations of the community of what physicians should be able to do to meet their needs in addition to the increased concerns of patient safety in todays' practice of medicine [7-9]. Enthusiasm for social accountability and cost-effectiveness of medical programs was also pressing and augmented by the rapid expansion in knowledge currently witnessed in the field of medicine [10-12]. It is not surprising therefore that many medical programs at undergraduate and postgraduate levels have adopted CBME in their curricula in expression of the set of aforementioned influences and to provide an evidence of their efforts to produce graduates who are qualified to meet the demands of their expected roles [4]. Organizing learning around a predetermined set of competencies encourages students and teachers to move toward common goals and promote active learning and student-centered approaches that are always sought and admired in modern medical education $[5,13,14]$.

\section{Characteristics of CBME}

CBME is different from traditional approaches of medical teaching in two prominent features. Firstly, while the traditional approach starts with a description of objectives and teaching intentions and the pedagogical methods to accomplish these, CBME starts with the end-product (graduate's abilities) in mind and then retrospectively defines the teaching and assessment strategies to ensure the achievement of these capabilities $[13,15]$. Secondly, while the duration of studies and credit hours are the means of merit in traditional approaches, CBME conceptually de-emphasizes time and entails that learning is centered around the demonstration of achievement of competency regardless of the time spent in the class [1, 2]. Despite the overwhelming popularity of CBME in current medical education programs, there are some obstacles yet to be addressed, particularly the definition of competencies and the development of authentic methods for their assessment [7].

\section{National competency frameworks for medical graduates}

The likelihood of CBME to endorse the desired professional competences of the twentyfirst-century physician in addition to the other benefits that it brought to the realm of medical education have endeared its use to ensure that medical graduates are well 
trained to suit the needs of their local communities [4]. The expansion in the number of medical schools, which is a global phenomenon mandated by growth in the population, and the changing criteria of health care systems have as well triggered the regulatory bodies in different parts of the world to think of ways to standardize and ensure equivalent outcomes of medical programs under their jurisdiction, particularly that fragmented curricula were claimed to hamper the quality of medical programs and their graduates in some countries [16]. This is translated in the yield of national competency frameworks that, although started in some parts of the world, are steadily expanding over other regions and courtiers [17, 18]. Examples of such frameworks include: the Canadian Medical Education Directives "CanMeds," the "Tomorrow's Doctor," the "Scottish Doctor" of the UK, the milestones of the Accreditation Council of Graduate Medical Education (ACGME) of the USA, and the Framework for Undergraduate Medical Education in the Netherlands $[13,18]$. Furthermore, many countries have attempted to embrace such initiatives in their basic as well as advanced medical training programs and the "Saudi Meds" is a notable example in the Middle East and the Arab region [19-24]. Such approach is deemed necessary to provide evidence that all medical graduates within a country are prepared to meet their expected roles according to a predefined set of national standards and to reflect quality assurance measures to internal and external relevant bodies $[20,24]$.

However, these frameworks are not meant to serve as curricula for medical schools, instead they are supposed to establish a common platform against which all basic medical curricula in a country can be compared and standardized [23, 24]. Thus, autonomy is preserved and as far as the standard competencies are addressed, medical schools are free to choose the teaching approaches appropriate to their settings and to include in their curricula topics which might be essential to suit their individual needs [24]. Some reports have shown that competency frameworks can be incorporated in the teaching strategy of medical programs regardless of the curriculum design and setup, be it traditional course-based, problem-solving-based, or community-oriented, as long as the essential competencies and authentic methods of their assessment are laid down [2, 25-27,]. This serves as another advantage of these frameworks and demonstrates their flexibility to be assimilated in different curricular approaches without affecting the integrity of the curriculum accustomed in a given educational setting. Initial evaluative studies of the implementation of competency frameworks have asserted some degree of success and increased the fortitude of adopting the strategy in many parts across the globe $[28,29]$. 


\section{The arena of medical education in the Sudan}

Medical education in Sudan is deeply rooted in the history of the country and the content of Africa beginning with the establishment of Kitchener Medical School in 1924 [30, 31]. Since that memorial event and for years later, the number of medical schools have increased gradually with the increased number of citizen practitioners and concomitant increase in the number of hospitals and other health facilities [30]. With an early generation of dedicated physicians who were trained inside and outside the Sudan in addition to the availability of opportunities for immense clinical training in rural and urban areas, the quality of medical training and its graduates have enjoyed a stance of an international reputation and a prestigious status for long time [30, 32, 33].

\section{The burst of medical schools in the Sudan}

Following an interesting period of constancy and good outcomes of basic medical education as mentioned earlier, the field has witnessed dramatic changes thereafter and with the constitution of the so-called "higher education revolution," the number of medical schools rose to 23 in 1990 and further spiked to 32 in the year 2014 [34]. However, that was only a part of the story, and in 2019 the number of medical schools drastically flared up to 74 ( 29 public and 45 in the private sectors; as retrieved from the website of the General Administration of Admission, Evaluation and Documentation of Higher Education Certificates - part of the Ministry of Higher Education and Scientific Research) [35], which means that the count of medical schools has exceeded the double in only five-year time. Moreover, those new medical schools are maldistributed across the country with the majority being located in the capital city of Khartoum while some are hosed in remote areas where the necessary infrastructure is almost non-existent $[30,32]$. One wonders about the justification of this massive increase in the number of medical schools in the absence of appropriate social and population studies and job market needs and, more importantly, the availability of enough clinical sites for training this huge and out-of-proportion number of medical students $[6,8,36]$. The unprecedented florid increase in the number of medical schools in Sudan that was once described as haphazard [32] will risk the whole phenomenon to be marked as a trade rather than natural professional development [34, 37, 38], bearing in mind that the establishment of a new medical school is a thoughtful and relatively long process that should involve careful planning and participation of all stakeholders $[6,39,40]$. 


\section{Implications to the quality of basic medical education}

It is well-known that clinical teaching lies at the heart of physicians' training as dictated by the apprenticeship model that is historically popular and well-grounded in the medical discipline [8]. However, with this unbalanced formula, the conditions of clinical training that was already in misery [41] is further jeopardized where the hospitals and other clinical sites suitable for training are stifled in the midst of the plethora of medical schools particularly around the city of Khartoum [32, 36, 42]. This perplexing situation is complicated with political and economic conflicts and has adversely affected the quality of clinical training and limited the clinical knowledge and skills of our medical graduates on whom we count for the well-being of the coming generations [41-43]. Regrettably, calls for thoughtful and commensurate expansion in the number of medical schools and medical students was reported almost 40 years ago with a visionary report about the directions of medical education in Sudan [44]. Considering the high rate of migration of Sudanese medical graduates seeking work and training outside and what is known as the "brain drain" phenomenon, it should be noted that expansion in medical education would not suffice alone to solve the shortage of physicians in the country unless accompanied with strategies to retain them in the health workforce [6, 36, 45, 46].

To this end, a clear and compelling evidence is apparent more than any time before for the medical education community and other stakeholders in Sudan to find robust mechanisms that guarantee quality and standardized medical training throughout the country. I believe that invention and implementation of a national competency framework for medical graduates in Sudan "SudanMeds" is one step forward in this long yet promising journey. In the following paragraphs, an account on the expected advantages of the proposed "SudanMeds" to the field of medical education in Sudan will be provided, in addition to some of the expected challenges and suggestions to overcome them.

\section{The promises of the "SudanMeds"}

The proposed national competency framework "SudanMeds" is expected to contribute positively to the realm of medical education in Sudan in many aspects that include but are not limited to improving the curricula of medical schools and aid the process of accreditation and quality assurance of their programs, ensuring minimum standards and equivalent products of medical education in the country, and facilitate transition of medical graduates to higher specialty training. These will be discussed later in further details. 


\section{Informing undergraduate medical curricula}

Curriculum development plays an important role in defining the quality of medical programs and their graduates $[27,45]$. The proposed competency framework would specify the competencies that should be mastered by all medical graduates in Sudan and consequently guide the process of identification of the important topics that should be covered in the curriculum. Decision on such topics should be tailored to encompass the pervasive health and environmental problems with intimate consideration of the social and cultural norms that are dominant in the country [6]. This is particularly essential considering the wide geographical area and the diverse ethnic and sociocultural backgrounds with which Sudan is endowed [30]. For instance, Sudan is characterized by the prevalence of communicable diseases (e.g., malaria, leishmania, tuberculosis) and non-communicable diseases (e.g., cancer and malnutrition), and it sometimes experiences environmental disasters like floods and sanitation problems [42]. Therefore, these topics should contribute to the core of the curriculum of medical schools in the country. Once the desired competencies of Sudanese medical graduates are defined, a list of enabling learning outcomes of knowledge and skills can be derived for each domain of the competency. In such a way a curriculum matrix of a minimum standard of knowledge/topics and skills domains can be created and used to inform development and standardization of basic medical curricula and ensure consistency in the outcomes of all medical schools in the country [24, 29, 47]. Fortunately, appreciable efforts are currently being made by some medical schools in Sudan in order to gain insight, analyze, and reform their curricula in a way that better suits their communities and serves their needs and one that may in turn set the stage for vigilant consideration of the proposed national competency framework [27, 30, 33, 48-50].

\section{Guard against significant omissions in the curriculum}

"SudanMeds" would also guard against significant omissions in the teaching program of medical colleges where the taught topics can be compared to a corresponding set of national standards $[23,24,51]$. Such omissions may create deficiencies in some vital skills and limit graduates' abilities to perform their expected roles as medical practitioners [51]. This is best exemplified by the report of the Medical Council in Sudan that affirmed significant deficiency and inconsistency in teaching professionalism across all medical schools [8]. A similar report has addressed inconsistencies in psychiatry and mental health teaching among medical schools with lack of either a separate disciplinary 
approach or appropriate clinical training [45]. Such deficiencies may only be examples of others $[48,52,53]$, particularly in view of the dilemma of the extremely rapid increase in the number of medical schools in the country as mentioned earlier. Considering the practice of adoption of old schools' curricula by new medical schools, a strategy that is well-known and practiced in Sudan [25, 27, 40], such significant omissions would lead to the reiteration of the same mistakes if those curricula were transferred without being compared to a national reference of standards [39]. Once "SudanMeds" is developed, all medical schools would be encouraged to map and cross-reference their curricula to the national standard, an exercise that would have a twofold advantage. It would offer medical colleges an opportunity for attentive foresight into their teaching practices and what they have been doing previously and simultaneously delineate and compensate for any deficiencies in their curricula $[23,51,54]$.

It should be noted that the proposed "SudanMeds" does not intend to replace curricula that are already administered in the medical colleges in Sudan, as it is not a formal curriculum. Instead, it would build on them and inform their reconstruction in a way that levers their capacities to produce competent graduates who are better prepared to serve their communities. Such variations in the curricula of medical colleges reflects diversity in a wide Country like the Sudan and is something that should be encouraged and consolidated.

\section{Relation to accreditation and quality assurance}

Recognition of medical programs by local, regional, and international regulatory bodies is steadily increasing and becoming a standard practice in the field exacerbated by the increasing concerns of quality assurance and cross-border migration of healthcare providers [38]. Medical schools are increasingly seeking recognition of their programs to provide an evidence of such quality requirements and to facilitate acceptance and engagement of their graduates in local, regional, and international jobs and training posts [54-56]. This process is gradually becoming mandatory not only in the Western world (e.g., the Liaison Committee of Medical Education in the USA and the General Medical Council in the UK) but also in some regional countries like Saudi Arabia, where medical schools are obliged to comply with the national competency framework, the "Saudi Meds" and the specifications of the National Centre for Academic Accreditation and Assessment (NCAAA) for their programs to be recognized in Saudi Arabia $[21,23,29,54]$. 
The Sudan Medical Council (SMC) and the Ministry of Higher Education and Scientific Research are the two regulatory bodies responsible for overseeing and accreditation of medical schools in Sudan [8]. The SMC, which was recently empowered by the recognition of the World Federation for Medical education (WFME), currently applies the concept of the "Model Medical School" based on the international standards set by the WFME in accreditation and recognition of basic medical programs in the country $[41,55,58]$. Although the WFME standards provide a comprehensive and internationally accepted platform for the accreditation of undergraduate medical programs, it neither recognizes individual medical colleges nor dictates what should be taught in the curriculum domain which is left to be decided based on the local health circumstances and traditional values prevalent within medical schools $[38,55,56]$. Of course, this is understood to confer flexibility since the WFME standards are intended to serve as a universal system for accreditation of basic medical education. The proposed "SudanMeds" would contribute here with a provision of a national skeleton of knowledge and skill domains; a curriculum content that should be assimilated in all basic medical programs as per the predefined set of competencies desired in Sudanese medical graduates [38]. Therefore, the framework is expected to offer a legitimate tool through which decisions on the content and coverage of basic medical programs' curricula can be determined and thus aid in the process of accreditation of medical schools in the Sudan [56].

\section{Facilitation of transition to training and job opportunities within the continuum of medical education in the Sudan}

It has been shown that national frameworks can be integrated horizontally across all medical schools and other allied health sciences and also vertically to involve higher specialty training programs [6]. In fact, national competency frameworks were introduced first in the setting of postgraduate medical training before being later incorporated in basic medical education $[23,29]$. Where national frameworks are integrated at all levels of medical training from basic to higher specialty onto continuing professional development, the trajectory of training in terms of competences is perceived as a journey through a continuum rather than movement between unrelated and isolated slots of learning [59]. As such, the transition of graduates from one level to the other, which is often associated with stress and difficulties [60], will be facilitated with the homogenous training environment created by adoption of well-developed and integrated national competency frameworks at all levels of medical education $[14,16]$. 


\section{In relation to training and work outside the Sudan}

Considering the experiences of development and adoption of national competency frameworks in some jurisdictions, it was evident that competency frameworks were first imparted from another country but then modified to suit the health and sociocultural characteristics prevailing in the place in which they will be applied [3, 13-15, 23, 29, 61]. As such, a bunch of similarity is expected between some local and international competency frameworks in terms of the capabilities and attributes of their trainees which may count to an easier transition of medical graduates should they decide to proceed for further training or work abroad $[21,62,63]$. Such similarities in the nature of the training and job requirements would create a sense of Camaraderie; feeling of friendliness or having spent some time together, between trainees or healthcare providers when they join a clinical environment of similar training and work demands and standards. Such factor may be of interest to the community of medical schools and other stakeholders in Sudan in view of the high rate of migration of their graduates to pursue further studies or work outside the country as mentioned earlier. It should be expected that the development of "SudanMeds" in itself would reflect the quality of basic medical education in Sudan and provide a firm basis on which decisions about the opportunities of Sudanese medical graduates for work and further training by regional and international bodies can be taken.

\section{Challenges to "SudanMeds"}

Having discussed some of the tenets and the expected benefits of the proposed "SudanMeds," it should be mentioned that some difficulties are also expected along the way. Apparently, the most critical challenge revolves around inducing an institutional and individual shift in the views and practices in the medical education community in Sudan to embrace competency-based teaching and buy-in the process of reforming curricula of medical schools accordingly $[3,14]$. Arguments like "if the old curriculum works, why should we change it" has been reported in some settings and should not be denied but refuted with the growing evidence of the benefits and applicability of national competency frameworks in the medical field worldwide [14]. Communication of the goals of such an intervention in addition to faculty development programs are among the strategies that can be used to decrease contention and resentment that may evolve among faculty and administrators [3, 4, 29, 64]. Other constraints include addressing 
the pressures of time and shortage of staff and the need for new educational technologies to teach and assess the desired learning outcomes and financial concerns tied to all of these aspects $[3,4,6,29,43]$.

\section{The way forward}

Consideration of ready-made competency frameworks set in regional and international countries as examples to be later modified to suit the circumstances of Sudan in addition to seeking the help of experts in the field could be illuminative initial steps in the road [15, 24]. Intuitively, a firm support to provide the necessary financial and logistical backup is essentially required from the top to the button of all those who are concerned including the government, the regulatory bodies, the civilian and public constitutions, and of course the medical school communities. Experiences from other parts of the world have shown that stunning and seamless achievements can be produced in such initiatives with collaboration of all stakeholders in the public and private sectors and their belief and perseverance to pursue the envisaged outcomes [14, 15, 23, 24, 28]. Although the road toward "SudanMeds" may appear long and daunting particularly within the intricate circumstances that Sudan is currently experiencing, the count is on the long heritage of courage and motivation of the Sudanese medical educators inside and outside Sudan to put-in the necessary efforts that would give birth to 'SudanMeds" and nourish it to grow and survive.

\section{Conclusion}

Resurgence of CBME in contemporary medical education programs is mandated by the changing roles and societal needs that physicians are currently facing. National competency frameworks for medical graduates are increasingly emerging and applied in different countries to ensure minimum standards in medical programs and equivalence of their outcomes based on the local needs of their communities. The "SudanMeds" is an initiative in the same direction necessitated by the unprecedented expansion in the number of medical schools ever seen in the country. The framework is expected to inform and standardize curricula of medical schools in Sudan and help with the accreditation of their programs with implications to quality assurance and readiness of their graduates to serve their communities. The development and implementation of such a framework is a challenge that requires contribution of all those who are concerned with medical education in Sudan, yet is promising in many aspects. 
This article calls for initiation of a discussion among all stakeholders about the feasibility, the perils, and the promises of a national competency framework for medical graduates in Sudan; the "SudanMeds."

\section{Conflict of Interests}

The author declares no conflict of interest.

\section{Acknowledgement}

The author would like to express his sincere gratitude to Professor Bashir Hamad for reviewing the article and enriching its content with his invaluable comments and eminent expertise.

\section{References}

[1] Gruppen L, Lypson M, Burkhardt J et al. (2016). Competency-based education: programme design and challenges to implementation. Medical Education. 50(5): 532-539.

[2] Burnette D (2016). The renewal of competency-based education: a review of the literature. Journal of Continuing Higher Education. 64(2): 84-93.

[3] Touchie C, Cate $O$ (2016). The promise, perils, problems and progress of competency-based medical education. Medical Education. 50(1): 93-100.

[4] Hawkins R, Simons K, Welcher C et al. (2015). Implementation of competencybased medical education: are we addressing the concerns and challenges? Medical Education. 49(11): 1086-1102.

[5] Frank J, Snell L, Cate O et al. (2010). Competency-based medical education: theory to practice. Medical Teacher. 32(8): 638-645.

[6] Girma T, Asaminew T, Siebeck M et al. (2016). Establishing medical schools in limited resource settings. Ethiopian Journal of Health Sciences. 26(3): 277-284.

[7] Frank J, Mungroo R, Ahmad Y et al. (2010). Toward a definition of competencybased education in medicine: a systematic review of published definitions. Medical Teacher. 32(8): 631-637.

[8] Karrar Z (2009). Professionalism and good medical practice: the role of Sudan Medical Council. Sudan Medical Journal. 45(2): 1-4. 
[9] Hassan K, Doumi A, Eltayeb B et al. (2009). Patients' satisfaction by information given to them by doctors concerning their illness and their views about the consent form signed before surgical procedures in Khartoum Teaching Hospital. Sudan Medical Journal. 45(2): 84-85.

[10] Gaffar AM, Magzoub M, Mahmoud I (2019). Do community-based medical schools produce more community-based research? A review of four medical schools in Sudan and Saudi Arabia. Health Professions Education. Retrieved from: https://doi. org/10.1016/j.hpe.2019.02.001

[11] Murray R, Larkins S, Russell H et al. (2012). Medical schools as agents of change: socially accountable medical education. Medical Journal of Australia. 196(10): 653.

[12] Boelen C, Woollard B (2009). Social accountability and accreditation: a new frontier for educational institutions. Medical Education. 43: 887-894.

[13] Harris P, Snell L, Talbot M et al. (2010). Competency-based medical education: implications for undergraduate programs. Medical Teacher. 32(8): 646-650.

[14] Smith S (1999). AMEE guide no. 14: outcome-based education: part 2-planning, implementing and evaluating a competency-based curriculum. Medical Teacher. 21(1): 15-22.

[15] Amin Z, Alshammary S (2015). CanMEDS curriculum in Saudi Arabian context: lessons learned and way forward. Journal of Health Specialties. 3: 206-211.

[16] Dalt L, Callegaro S, Mazzi A et al. (2010). A model of quality assurance and quality improvement for post-graduate medical education in Europe. Medical Teacher. 32(2): e57-e64.

[17] Tang K, Yang Y, Chu J et al. (2019). From indifference to internalisation: the definition of good doctors by CanMEDS Roles. Medical Education. 53(5): 498-528.

[18] Ellaway R, Roy K, Preston R et al. (2018). Translating medical school social missions to student experiences. Medical Education. 52(2): 171-181.

[19] Boker A (2016). Toward competency-based curriculum: application of workplacebased assessment tools in the National Saudi Arabian Anesthesia Training Program. Saudi Journal of Anesthesia. 10(4): 417-422.

[20] Liu, Z., Tian, L., Chang, Q., et al. (2016). A competency model for clinical physicians in china: a cross-sectional survey. PLOS ONE. 11(12): e0166252.

[21] Tekian A, Al Ahwal M (2015). Aligning the SaudiMED framework with the National Commission for Academic Accreditation and Assessment domains. Saudi Medical Journal. 36(12): 1496-1497. 
[22] Mirzazadeh A, Hejri S, Jalili M et al. (2014). Defining a competency framework: the first step toward competency-based medical education. Acta Medica Iranica. 52(9): 710-716.

[23] Al Bu Ali W, Balaha M, Kaliyadan F et al. (2013). A framework for a competency based medical curriculum in Saudi Arabia. Materia Socio Medica. 25(3): 148-152.

[24] Zaini R, Abdulrahman K, Al-Khotani A et al. (2011). Saudi Meds: a competence specification for Saudi medical graduates. Medical Teacher. 33(7): 582-584.

[25] Husain N, Elsheikh N, Elsheikh M et al. (2018). Final year medical students and professionalism: lessons from six Sudanese medical schools? Journal of Public Health and Emergency. 2: 27.

[26] Elamin S, Ahmed A, Ovla H et al. (2018). Community-based medical education from gezira medical students' perspective. Journal of Medical Education. 17(4): 215-221.

[27] Ahmed Y, Alneel S (2017). Analyzing the curriculum of the faculty of medicine, University of Gezira using Harden's 10 questions framework. Journal of Advances in Medical Education \& Professionalism. 5(2): 60-66.

[28] Busari J, Verhagen E, Muskiet F et al. (2008). Implementation of a competencybased residency curriculum: experiences from a resource-limited environment in the Caribbean. Medical Teacher. 30(9-10): e189-e195.

[29] Frank J, Danoff D (2007). The CanMEDS initiative: implementing an outcomesbased framework of physician competencies. Medical Teacher. 29: 642-647.

[30] Fahal A (2007). Medical education in the Sudan: its strengths and weaknesses. Medical Teacher. 29: 910-914.

[31] Khalil S (2015). Physicians of Sudan: historical perspective. Sudan Medical Journal. 51(1): 53-58.

[32] Bayoumi A (2018). Critical analysis of education in medicine and health sciences in Sudan 2010-2014. Journal of Medical Education and Training. 2: 037.

[33] Sukkar MY (1977). Medical Education. Sudan Medical Journal. 15(2): 63-64.

[34] Mutwali I, Omer A, Abdalhalim S (2015). Why a medical career? What makes Sudanese students to join a medical college and pursue a medical career? World Journal of Education. 5(2): 19-25.

[35] General Administration of Acceptance, Evaluation and Documentation of Higher Education Certificates. Retrieved from: daleel.admission.gov.sa

[36] EIMakki M (2015). Health service, teaching medical students and training of residents in Khartoum as applied to the surgical specialty. Sudan Medical Journal. 50(2): 1-3. 
[37] Mullan F, Frehywot S, Omaswa F et al. (2011). Medical schools in sub-Saharan Africa. Lancet. 377: 1113-1121.

[38] Karle H (2008). International recognition of basic medical education programmes. Medical Education. 42(1): 12-17.

[39] Gordon D (2016). Criteria for establishment of a new medical school: guidance for governments, regulators and universities. Retrieved from: https://wfme.org/ download/new-medical-school/

[40] Hamad B (1999). Establishing community-orientated medical schools: key issues and steps in early planning. Medical Education. 33(2): 382-389.

[41] Mahgoub E (2010). The dilemma of medical education in the Sudan. Sudan Medical Journal. 46(1): 2-3.

[42] Ebrahim E, Ghebrehiwot L, Abdalgfar T et al. (2017). Health care system in Sudan: review and analysis of strength, weakness, opportunity, and threats (SWOT analysis). Sudan Journal of Medical Sciences. 12(3): 133-150.

[43] Nurelhuda N, Yousif A (2017). Generic skills training through interprofessional peerassisted learning. Medical Education. 51(11): 1162-1188.

[44] Sukkar M, Beleil O (1975). Current directions of medical education in the Sudan. Sudan Medical Journal. 13(4): 153-166.

[45] El Tahir M, Elsheikh A, Abodoum A et al. (2019). Evaluation of undergraduate sychiatric teaching in Sudan. BJPsych International. 16(1): 13-15.

[46] Greysen S, Dovlo D, Olapade-Olaopa O et al. (2011). Medical education in subSaharan Africa: a literature review. Medical Education. 45(10): 973-986.

[47] Bates J, Schrewe B, Ellaway R et al. (2019). Embracing standardisation and contextualisation in medical education. Medical Education. 53(1): 15-24.

[48] Nurelhuda N, Morahan P, Hamad B et al. (2018). Incorporating community-based education to develop socially responsible Sudanese dentists. Medical Education. 52(1): 1180-1209.

[49] Gismalla M (2017). Teaching procedures and skills in medical schools: gaps, weakness, and challenges. Sudan Journal of Medical Sciences. 12(1): 46-51.

[50] Awadalla M, Abdalla A, Taha S (2017). Graduates perception towards instructional methods of emergency medicine: affecting their self-confidence in emergency departments. Sudan Journal of Medical Sciences. 12(4): 207-214.

[51] Ellaway R, Evans P, Mckillop J et al. (2007). Cross-referencing the Scottish Doctor and Tomorrow's Doctors learning outcome frameworks. Medical Teacher. 29(7): $630-635$. 
[52] Osman T (2016). Medical students' perceptions towards research at a Sudanese University. BMC Medical Education. 16: 253.

[53] Doumi A, Hassan K, Eltayeb B et al. (2009). Patients' complaints against their treating doctors at the Sudan Medical Council 2005-2008. Sudan Medical Journal. 45(2): 82-83.

[54] Vallance A, Higham J (2011). A toolkit to meet Tomorrow's Doctors standards. Medical Education. 45(5): 508-535.

[55] Karrar Z (2018). Global trends in quality assurance in medical education: implications and challenges to medical education in Sudan. Khartoum Medical Journal. 11(3): 1518-1523.

[56] Zanten M, Norcini J, Boulet J et al. (2008). Overview of accreditation of undergraduate medical education programmes worldwide. Medical Education. 42: 930-937.

[57] Sethi A, Javaid A (2017). Accreditation system and standards for medical education in Pakistan: it's time we raise the Bar. Pakistan Journal of Medical Sciences. 33(6): 1299-1300.

[58] Ahmed H, Elzien A (2007). Global standards in basic medical education: Are they suitable for accreditation of schools of medicine in developing countries? Sudanese Journal of Paediatrics. 8: 48-65.

[59] Czabanowska K, Klemenc-Ketis Z, Potter A et al. (2012). Development of a competency framework for quality improvement in family medicine: a qualitative study. Journal of Continuing Education in the Health Professions. 32(3): 174-180.

[60] Teunissen P, Westerman M (2011). Opportunity or threat: the ambiguity of the consequences of transitions in medical education. Medical Education. 45: 51-59.

[61] Khoo S, Lahiri M, Huggan P (2014). When traditional model meets competencies in Singapore: beyond conflict resolution. ANNALS Academy of Medicine Singapore, 43: 544-549.

[62] Lineberry M, Osta A, Barnes M et al. (2015). Educational interventions for international medical graduates: a review and agenda. Medical Education. 49(9): 863-879.

[63] Ringsted C, Hansen T, Davis D et al. (2006). Are some of the challenging aspects of the CanMEDS roles valid outside Canada. Medical Education. 40(8): 807-815.

[64] Caccia N, Nakajima A, Scheele F et al. (2015). Competency-based medical education: developing a framework for obstetrics and gynaecology. Journal of Obstetrics and Gynaecology Canada. 37(12): 1104-1112. 